\title{
Caproic acid production from lactate using Megasphaera hexanoica
}

Seongcheol Kang ${ }^{*}$, , Hyunjin Kima ${ }^{a}$ Byoung Seung Jeon ${ }^{b}$, Okkyoung Choi ${ }^{a}$, and Byoung-In Sang ${ }^{a}$

* middle7sch@gmail.com

a Department of Chemical engineering, Hanyang University, Republic of Korea; ${ }^{b}$ Centrum for Applied Geosciences, University of Tübingen, Germany

\section{HIGHLIGHTS:}

- Megasphaera hexanoica can metabolize lactate to produce caproic acid.

- High yield of caproic acid was achieved.

- Caproic acid production per unit cell concentration under lactate condition was higher than that of fructose condition.

BACKGROUND: Lactate can be readily produced from carbohydrate-rich wastes such as food waste by environmental microorganisms and used as an electron donor to produce various medium chain carboxylic acids(MCCAs) through chain elongation process [1]. Although MCCAs production from various wastes using microbial communities has been conducted $[2,3]$, there have been few reports of isolated strains capable of producing MCCAs from lactate. In this study, we showed Megasphaera hexanoica, a bacterial strain known to produce MCCAs from fructose, can metabolize lactate to produce caproic acid. The yield and rate of caproic acid production using lactate were also investigated and compared with the results using fructose.

RESULTS \& DISCUSSION: Using lactate as an electron donor, caproic acid production was observed in acetate and butyrate containing medium. Although the cell growth of $M$. hexanoica using lactate was much lower than using fructose, the titre of caproic acid showed no significant difference. Under lactate condition $9.3 \mathrm{~g} / \mathrm{L}$ of caproic acid was produced and $0.3 \mathrm{~g} / \mathrm{L} / \mathrm{h}$ of caproic acid production rate was achieved. In addition, when using lactate, the amount of caproic acid per unit cell concentration was over 2 times higher than using fructose.

CONCLUSION: $M$. hexanoica metabolized lactate to produce caproic acid and achieved high titre of $9.3 \mathrm{~g} / \mathrm{L}$. Increasing the cell concentration of $M$. hexanoica in the condition of using lactate is expected to improve caproic acid productivity. Since this strain appears to have high MCCAs production capacity under lactate conditions, it can be applied to produce MCCAs in the lactate fermentation with various wastes. 

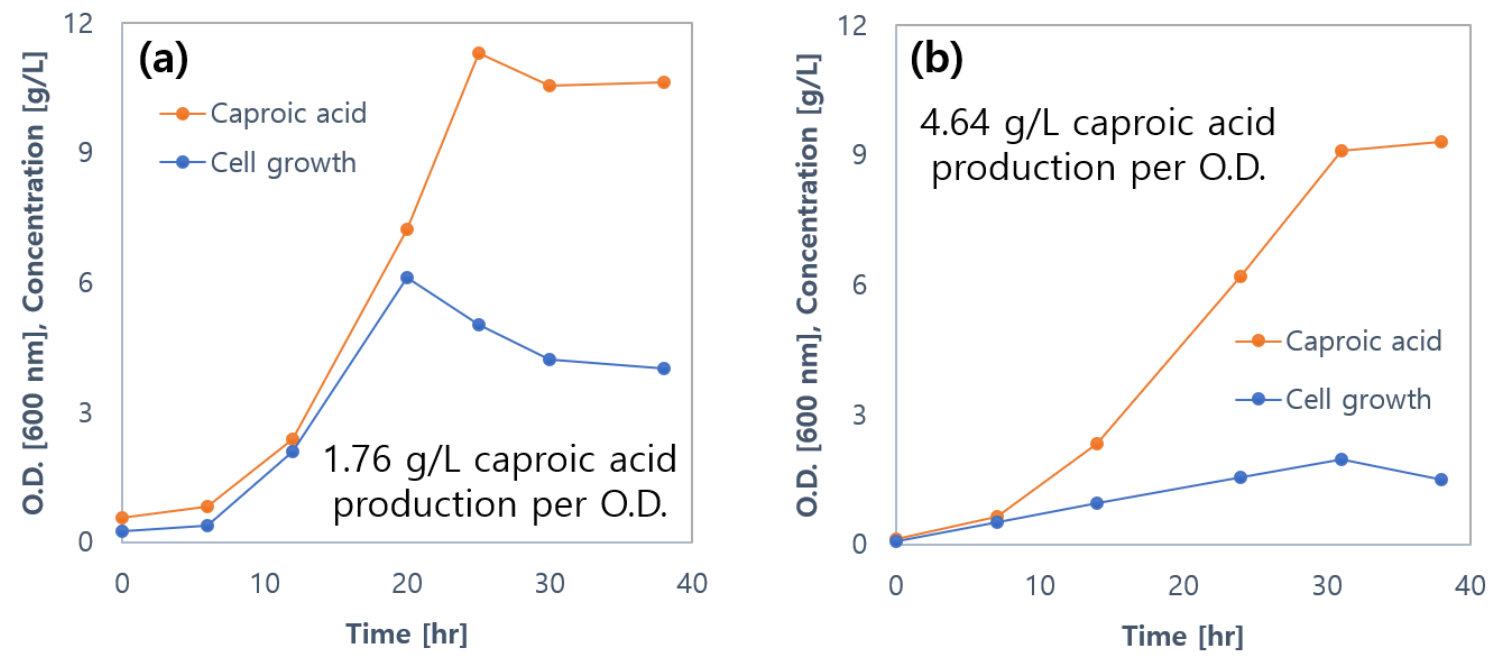

Figure 1. Cell growth and caproic acid production of Megasphaera hexanoica (a) with fructose, (b) with lactate.

\section{REFERENCES}

1. Wu, Q., Guo, W., You, S., Bao, X., Luo, H., Wang, H., \& Ren, N. (2019), Concentrating lactate-carbon flow on medium chain carboxylic acids production by hydrogen supply., Bioresource Technology, 291, 121573

2. Duber, A., Jaroszynski, L., Zagrodnik, R., Chwialkowska, J., Juzwa, W., Ciesielski, S., \& Oleskowicz-Popiel, P. (2018). Exploiting the real wastewater potential for resource recovery-N-caproate production from acid whey., Green Chemistry, 20, 3790

3. Angenent, L. T., Richter, H., Buckel, W., Spirito, C. M., Steinbusch, K. J. J., Plugge, C. M., ... Hamelers, H. V. M. (2016). Chain Elongation with Reactor Microbiomes: Open-Culture Biotechnology to Produce Biochemicals., Environmental Science and Technology, 50, 2796-2810 